\title{
A PORTABLE SCOTOMETER
}

BY

\section{J. P. Spencer Walker}

HOVE

IN charting a scotoma we have all noticed that some patien⿷⿱乛龰⿱中⿰㇀丶㇀ have a difficulty in telling the exact moment of disappearance the " moving spot." This difficulty may be caused by an uneved illumination of the chart, of the "moving spot" itself, or by reflecting points or surface of the spot-carrier. This difficulty h been overcome by the Projection Scotometer. In such a scoto. meter, the instrument is behind the patient. Both the fixation and the "moving spots" are projected on to the wall facing the patient. On trying this instrument I was struck with the ease with which I was able to tell the exact moment of the disappearanco of the "moving spot" of light. This projection scotometer $B$ excellent for Institutions, but has the disadvantage of lack of portability. It occurred to me that if a portable scotometer coutie be devised, using a " moving spot" of light over a matt blacecos surface, it would be of great use, not only in the consulting room? but also in those cases which have to be examined in the patient house.

A scotometer has been made for me by Messrs. Rayner. instrument folds into its case, in which there is room for spare charts, and there are no loose parts, except the rod carrying the " moving spots," which may be clipped into the lid. The instruo ment is provided with an adjustable chin-rest, and a chart-holder in the centre of which there is a small hole, and behind this hol is a small bulb lit by a pocket battery. This point of light is the fixation spot. The charts are printed in the usual manner, but have a matt black surface on the reverse side. There is also small central hole. The chart is inserted with the black surface facing the patient, and its central hole coinciding with the hole in the chart. The "moving spot" of light is obtained by a rod on the tip of which, is a small hole. This hole is illuminated by a pocket battery in the rod handle. The rod is furnished with a rotating disc of coloured glasses, so that the colour of the spot can be turned from white to red or green etc., as desired. Immediately behind the hole is a pin point with a spring guard and below it is a square block of metal. The rod is placed over the chart with the square block touching it. It is then move over the chart in the desired position, keeping the block in contact with the chart all the time. This is most important, as if the

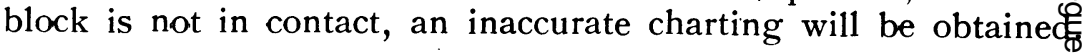




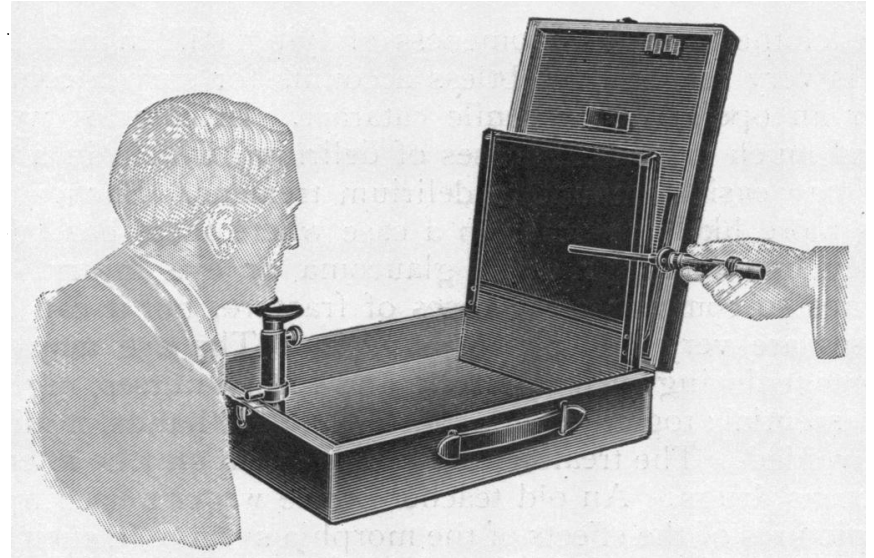

As soon as the patient says that the light has gone, a slight pressure on the chart with the rod will bring the pin point into action and a prick will be made on the chart. After the scotometer has been adequately " pricked" the chart is removed and reversed. A line is then drawn in the usual manner joining the pin pricks.

The advantages of this method of charting are that the patient's attention is not diverted by any shining points on the surface of the carrier of the "moving spot" nor by the operator's hand. Also it avoids the difficulty of even illumination of the chart itself. The chart having a matt black surfare presented to the patient conceals the moving rod sufficiently to concentrate his attention on the spot of light. The instrument works well in a subdued light and a completely dark room is unnecessary. The bulbs and battery are of the ordinary pocket torch type. The eye that is not being examined may be totally occluded, or a trial frame may be used with a stenopaeic disc of small aperture allowing this eve to see the fixation spot only. The use of a stenopaeic disc allows both eyes to fix on the central spot, and so has many advantages.

I have used this scotometer for about eighteen months and have found it successful.

\section{ANNOTATION}

\section{Post-operative Delirium}

Among the rarer sequelae of ophthalmic operations may occur post-operative delirium. As a rule, in the aged, this is of low degree and does not go much beyond muttering and picking 